\title{
APROXIMACIONES FILOSÓFICO-LINGÜÍSTICAS AL DESAFÍO LÓGICO DE LA AUTOFICCIÓN EN TEXTOS DE J. CERCAS Y PÉREZ-REVERTE
}

\author{
PHILOSOPHICAL AND LINGUISTIC APPROACHES TO THE LOGICAL \\ CHALLENGE WITH AUTOFICTION IN J. CERCAS AND PÉREZ-REVERTE'S \\ TEXTS
}

\author{
José Antonio CALZÓN GARCíA \\ Universidad de Vilnius (Lituania) \\ joseantoniocalzon@gmail.com
}

Resumen: El artículo, tomando como punto de partida algunos textos de y sobre Javier Cercas y Arturo Pérez-Reverte, analiza los problemas lógicos subyacentes en los relatos autoficcionales, utilizando distintas herramientas -lógica difusa, teoría de conjuntos o teoría de la relevancia - procedentes de la filosofía y la lingüística, para aportar algo de luz a las situaciones paradójicas que ofrecen los relatos en los cuales el autor tiene una ambigua relación de identificación con el protagonista y/o con el narrador. El objetivo es incorporar nuevas herramientas de análisis y comprensión a un género contradictorio en el cual la crítica fundamentalmente se ha preocupado por la búsqueda de definiciones, categorizaciones y descripciones.

Palabras clave: Autoficción. Lógica difusa. Teoría de conjuntos. Javier Cercas. Arturo Pérez-Reverte.

Abstract: This article focuses on the logical problems observed in autofictional stories such as written by Javier Cercas and Arturo Pérez-Reverte, by using a variety of tools - fuzzy logic, set theory, relevance theory - from philosophy and linguistics, in order to throw light on the paradoxical situation when we read stories in which the author shows an ambiguous relationship, in terms of identity, with the protagonist and/ or with the narrator. The aim is to use new tools in order to analyse and understand this contradictory genre about which critics use to worry about definitions, categorizations and descriptions.

Key Words: Autofiction. Fuzzy Logic. Set Theory. Javier Cercas. Arturo Pérez-Reverte. 


\section{INTRODUCCIÓN}

En el año 2005, tras el éxito de la arrolladora novela Soldados de Salamina (2001), el escritor Javier Cercas publicaba La velocidad de la luz, una obra en la cual el protagonista - quien presentaba notables concomitancias con el autor de la obra-, en primera persona, relataba sus experiencias como profesor en la universidad estadounidense de Urbana (Illinois). En ese tiempo coincidirá con Rodney Falk, un veterano de la guerra de Vietnam, quien se convertirá a su vez en confidente y compañero del profesor español. Durante el tiempo de estancia en América el protagonista le confesará a su colega que está escribiendo una novela, sobre la cual aún se abría para él todo un horizonte de dudas:

Le expliqué que lo único que tenía claro en mi novela era precisamente la identidad del narrador: un tipo exactamente igual que yo que se hallaba exactamente en las mismas circunstancias que yo. "Entonces el narrador eres tú mismo?", conjeturó Rodney. "Ni hablar", dije, contento de ser ahora yo quien conseguía confundirle. "Se parece en todo a mí, pero no soy yo". Empachado del objetivismo de Flaubert y de Eliot, argumenté que el narrador de mi novela no podía ser yo porque en ese caso me hubiera visto obligado a hablar de mí mismo, lo que no sólo era una forma de exhibicionismo o impudicia, sino un error literario, porque la auténtica literatura nunca revelaba la personalidad del autor, sino que la ocultaba. "Es verdad", convino Rodney. "Pero hablar mucho de uno mismo es la mejor manera de ocultarse" (Cercas, 2005: 62).

Cambiando de autor - que no de impostura-, nos encontramos, entre otras narrativas, con la de Arturo Pérez-Reverte, quien, en palabras de Cambosu (2007: 327), afirmará reconocer en el texto, a propósito de su obra El pintor de batallas (Pérez-Reverte, 2006), "su propia biografía y su propia mirada pero no la identidad con el protagonista". De igual modo, tiempo más tarde, entrevistado como consecuencia de la publicación de su novela Hombres buenos (Pérez-Reverte, 2015), el escritor de Cartagena comentará de nuevo, en relación a uno de sus personajes: "es un tipo que se parece a mí, pero no soy yo. Es un artefacto narrativo" (Antón, 2015).

Las muestras seleccionadas no son sino un pequeño ejemplo de un amplísimo conjunto de obras, críticas y valoraciones que en las últimas décadas han servido como vehículo para la expresión o el análisis de una categoría literaria tan incómoda como inasible: la autoficción. Las próximas páginas pretenden ser un proceso de indagación, no tanto en las características o definición del citado fenómeno, sino en el callejón sin salida al que parece abocar uno de sus elementos nucleares, tal y como hemos ilustrado 
con los ejemplos introductorios: la antinómica relación de identidad y diferencia que los autores marcan con sus criaturas literarias. Es decir, desde nuestra posición, en cuanto críticos y lectores, ¿cómo hemos de enfrentarnos al universo paradójico que envuelve a la autoficción? ¿Es posible apelar a la racionalidad para el estudio de unas manifestaciones literarias que desde su propia constitución optan por el juego, la máscara y el fingimiento?

\section{AUTOFICCIÓN: HISTORIA DE UN DESENCUENTRO}

Desde que, en 1977, Serge Doubrovsky definiera el término autofiction (Gómez Trueba, 2009: 67), escribiendo una obra, Fils, en la que se combinaba la narrativa de ficción con la autobiografía, y en la que el nombre del autor y el del personaje principal era el mismo, han corrido ríos de tinta acerca de un fenómeno literario’ que, en esa misma década de los años 70, permitía a Roland Barthes publicar su Roland Barthes par Roland Barthes (1975), una autobiografía "que utiliza el recurso de la tercera persona narrativa para hablar de sí mismo, adjuntando al mismo tiempo imágenes de su álbum de fotos, profesional y personal" (Fáix, 2013: 131). También en 1975, y como acicate para la acuñación de Doubrovsky, Philippe Lejeune, en Le pacte autobiographique, plantearía la dificultad que supone hablar de pacto novelesco cuando existe identidad entre narrador y autor, abriendo la puerta a un problema para los críticos que ha durado hasta hoy. A su vez, en un juego de retroalimentación, el propio Lejeune se haría eco, algo más tarde (1980), del neologismo popularizado por Doubrovsky a través de su libro Je est un autre (Amícola, 2009: 192)².

Si bien es habitual considerar la autoficción como un género netamente contemporáneo, el cual habría comenzado a vivir su época dorada a partir de 1970 (Amícola, 2009: 192) —-momento en el cual la sospecha cunde tanto en el territorio de la ficción como alrededor de la supuesta verdad autobiográfica-, lo cierto es que ya hay quienes remiten a la Grecia clásica, y en concreto a Luciano de Samosata (Amícola, 2009: 184), a la hora de hablar de los orígenes de una práctica textual que, con el discurrir del tiempo, y en el ámbito concreto de nuestra literatura, habría podido tener entre sus pioneros a Juan Ruiz, el Arcipreste de Hita (2006), al autor del Lazarillo de Tormes (Calzón García, 2015) o al mismísimo Larra (Molina Foix, 2009): "Larra es el primer fabricante del

1 Sobre la escritura autobiográfica y la autoficción, véanse tanto las pioneras publicaciones de Romera Castillo $(2006,2010)$ como las actividades realizadas, bajo su dirección, en el Centro de Investigación de Semiótica Literaria, Teatral y Nuevas Tecnologías (en http://www2.uned.es/centro-investigacion-SELITEN@T/ escritura_autobio.html), entre las que se cuentan, por ejemplo, las investigaciones de Molero de la lglesia (2000a, 2000b). Véase también, más recientemente, la compilación de ensayos al respecto en Casas (2014).

2 La crítica francesa ha desarrollado desde entonces una notable producción analítica al respecto. Podemos citar, como ejemplos, los trabajos de Genette (1991, 2004), Lecarme (1993), Darrieussecq (1996), Montremy (2002), Colonna (2004) o Gasparini (2004), entre otros. 
yo al por mayor en la literatura española [...] lo de Larra no eran pseudónimos [...] sino heterónimos avant la lettre: a cada una de sus encarnaciones les daba distinta voz y función [...] Larra inventó el periodismo del yo".

La propia definición del género, a juzgar por los esfuerzos críticos que se han desarrollado en los tiempos recientes, aumenta aún más la inasibilidad conceptual de este. Así, en términos muy sencillos, Agustí Farré (2006: 10) considera que la autoficción "es una especie de autobiografía novelada". Otros, como Alberca (2005-2006: 115-116), presentarán más pausadamente la caracterización del género:

La autoficción es un relato que se presenta como novela, es decir, como ficción, o sin determinación genérica (nunca como autobiografía o memorias), se caracteriza por tener una apariencia autobiográfica, ratificada por la identidad nominal de autor, narrador y personaje [...] Este cruce de géneros configura un espacio narrativo de perfiles contradictorios, pues transgrede o al menos contraviene por igual el principio de distanciamiento de autor $y$ personaje que rige el pacto novelesco y el principio de veracidad del pacto autobiográfico.

En cualquier caso, será el propio Alberca (2007: 158) quien establezca un acuerdo de mínimos a la hora de entendernos en torno a este corpus textual: "una autoficción es una novela o relato que se presenta como ficticio, cuyo narrador y protagonista tienen el mismo nombre que el autor". Es decir, en líneas generales hay cierto consenso a la hora de considerar que la autoficción es un tipo de texto literario más cercano a la ficción que al documento, en el cual el autor busca - o al menos no rechaza, desde el plano puramente narrativo (Vila Sánchez, 2015: 128)—su identidad —nominal y/o biográficacon el narrador y uno de los personajes, habitualmente el protagonista.

No obstante, y al margen de la polémica en torno a su definición, así como a la adscripción de los textos a la citada categoría, lo cierto es que el universo autoficcional adquiere múltiples ramificaciones en función de la laxitud o, en palabras de Alberca (1996), ambigüedad con la que los autores parecen moverse entre realidad y ficción. Así, según Alberca, para que se dé ese pacto ambiguo son necesarios: a) unos hechos claramente autobiográficos; b) otros ficticios, que el lector puede reconocer como imposibles de atribuir al autor, y c) una tercera clase de hechos que podrían ser y no ser autobiográficos, y cuya atribución es prácticamente insoluble para el lector. La suma, pues, de estas tres clases de elementos determinaría la ambigüedad en estos textos.

En resumidas cuentas, sin hacer un repaso exhaustivo del tema, la autoficción se ha venido mostrando como un tipo de narración en la cual el lector cree encontrar al autor, de una u otra forma, dentro del texto. Ante ello, el intérprete se ve inerme frente al 
reto que supone, en el acto de lectura, verificar la credibilidad histórica real de los datos aportados, y las posturas generalmente ambiguas, cuando no paradójicas, de los autores reales, a la hora de hablar de sus propias creaciones, no ayudan para analizar el texto con unas coordenadas nítidas.

¿Qué hacer pues, en este caso? Las próximas páginas pretenden precisamente ahondar en esta cuestión, aportando herramientas analíticas que permitan escapar al cul-de-sac de la autoficción, desde la racionalidad que supone asumir que, al margen de las veleidades del autor, desde un punto de vista intra y extratextual, los textos que presentan características autoficcionales no son en modo alguno bestias indómitas ante las cuales asumir con resignación el "solo el autor lo sabe". Hora es ya de ofrecer al lector cauces explicativos que le permitan tomar la iniciativa interpretativa, al margen del postureo "sí pero no" autorial.

\section{LOS CAMINOS DIFUSOS DE LA AUTOFICCIÓN}

A la hora de hablar de la producción autobiográfica de las últimas décadas, Gómez Trueba (2009: 81) apunta como una constante "el planteamiento en el discurso de la imposibilidad de identidad con el referente, con la consiguiente puesta de manifiesto de los borrosos límites entre autobiografía y ficción". Esta borrosidad puede a su vez ser consecuencia de la estructura especular en algunos de estos textos, cuando el autor "se refleja en el personaje ficticio que es, a su vez, narrador de esa otra novela que estamos leyendo a medida que se está escribiendo" (Ramos Ortega, 2006: 87), pero también cuando la historia es un espejo deformante en el que el autor, a través del personaje, se muestra ante nosotros.

La idea de borrosidad, a la hora de hablar de la autoficción, ha corrido pareja con la de mestizaje (Lluch Prats, 2006: 304), en la medida en que este género es, o parece ser, la máscara que envuelve a la literatura con vida, o a la mentira con verdad, a partir de los dudosos límites entre autor y obra. Ahora bien, si con Alberca (2007: 67) asumimos que el pacto autobiográfico se basa en los principios de identidad y veracidad, ¿hacia dónde nos lleva la autoficción? Si en esta "el objetivo del novelista está en hablar de sí mismo sin responsabilizarse por ello del enunciado" (Molero de la Iglesia, 2006), ¿cuánto hay de impostura en el género? ¿Desde qué coordenadas podemos analizar manifestaciones textuales en las cuales el autor es y no es el protagonista?

Peña (1988: 3 y 7), a la hora de hablar de los desafíos filosóficos de la categorización, apuntaba la necesidad inexcusable de reconocer el principio de gradualidad, en función del cual todas las diferencias son de grado. Nada nuevo, pues, en el horizonte de la lógica popular. Sin embargo, el análisis de esta reflexión desde la noción de conjuntos difusos suponía asumir que la realidad era encasillable a partir de divisiones franqueables, 
respecto a las cuales los objetos, o las ideas, podrían tener diferentes grados de pertenencia.

Recordemos brevemente que se considera a Lofti A. Zadeh como el padre, o al menos el impulsor, de lo que ha venido en llamarse lógica difusa. Para Zadeh (2008: 2751) "fuzzy logic is not fuzzy. Basically, fuzzy logic is a precise logic of imprecision and approximate reasoning [...] which transforms an object, $P$, into an object $P^{*}$, which in some specified sense is defined more precisely than $P^{\prime \prime}$. De este modo, la lógica difusa tendría la capacidad de volver racionales decisiones en un contexto de falta de precisión, falta de certeza, información incompleta, información en conflicto, etc. Para Zadeh (2008), como para Peña (1988), los conceptos manejados por la ciencia son graduales, y no bivalentes:

In science it is traditional to define concepts in a bivalent framework [...] The problem is that, in reality, many concepts in science are fuzzy, that is, are a matter of degree [...] The problem is that natural languages are intrinsically imprecise. Imprecision of natural languages is rooted in imprecision of perceptions. A natural language is basically a system for describing perceptions. Perceptions are intrinsically imprecise, reflecting the bounded ability of human sensory organs, and ultimately the brain, to resolve detail and store information. Imprecision of perceptions is passed on to natural languages [...] Science deals not with reality but with models of reality. More often than not reality is fuzzy. For this reason, construction of realistic models of reality calls for the use of fuzzy logic rather than bivalent logic (Zadeh, 2008: 2769-2770).

Para Zadeh (2008: 2771 y 2776), a pesar de lo refractarias que han sido las ciencias humanas y sociales a la incorporación de tal disciplina, su uso ayudaría a comprender de forma más natural y precisa fenómenos enraizados en nuestra realidad inmediata: "the issue of imprecision has been and continues to be largely ignored in the literatures of linguistics and philosophy of languages [...] fuzzy logic [...] serves as a cointensive model of reality, especially in humancentric fields such as law, linguistics and psichology".

En el ámbito hispano, autores como Gomila (2013: 7) han apuntado también que la vaguedad, la borrosidad y la indeterminación semántica dejan en algunos casos de ser vistas como un defecto del que adolece el lenguaje, y pasan a ser contempladas como la consecuencia de nuestra arquitectura cognitiva y de la estructura continua y dinámica de la realidad. En cualquier caso, no está muy difundida aún la distinción entre la borrosidad de la intelección y la borrosidad del objeto (Almela Pérez, 2003: 66), lo que supone, de algún modo, enfrentarse al problema ontológico de ubicar el ámbito de lo difuso, bien en la realidad extramental, bien en los procesos intelectivos de aprehensión 
del mundo sensible. Así, por ejemplo, la paradoja sorites - que se preguntaría por la cantidad de granos de arena necesarios para formar un montón- no hace más que poner de manifiesto cómo nuestra realidad nos enfrenta a situaciones que escapan al encorsetamiento del pensamiento binario.

Volviendo al ámbito de la autoficción, lo cierto es que la lógica difusa ofrece, o pudiera ofrecer, cauces explicativos con los que escapar del callejón sin salida al que nos lleva al alternativa de identificar, o no, al autor con el protagonista. El propio Alberca (2005-2006: 119), de algún modo, alude a ello cuando señala que la autoficción "permite precisar el gradualismo variable y complejo con que el lector tiene que descifrar estos textos situados a caballo de los dos grandes pactos narrativos, el autobiográfico y el ficticio". En ese "pacto ambiguo" en el que se mueven las autoficciones, con un personaje que es y no es a la vez el autor, nos enfrentamos a un discurso con diferentes maneras y grados de autobiografismo, oscilando entre la ficción y el documento, una suerte de "territorio indefinido", en palabras del escritor Javier Marías (Manrique Sabogal, 2008).

Lo cierto es que contemplar los textos autoficcionales en cuanto narraciones difusas permite alejarse del problema realidad / ficción, a partir de una interpretación graduada de la presencia autorial en el texto. La pregunta, sin embargo, seguiría siendo: bien, ¿y eso supone un avance? En primer lugar, desde un punto de vista difuso, la presencia autorial a través de alguno de los personajes —normalmente el protagonista si hablamos de autoficciones - puede ser analizada en clave de autobiografemas, esto es, de unidades mínimas alusivas, de algún modo, a las características personales del autor: nombre, rasgos físicos, localización espacial, estudios, etc. En cualquier caso, y aunque esto ayudaría a refinar la búsqueda de huellas autoriales en el texto, el problema seguiría estando latente, esto es: si el protagonista confiesa, digamos, haber vivido en Milán, ¿acaso el Milán de la novela es el mismo que el del universo extraliterario, o de nuevo habría que recurrir a explicaciones difusas, y hablar de distintos grados de milanidad?

En realidad, la cuestión crucial en todo este embrollo parece ser no tanto el hecho de descomponer la identidad autobiográfica en minúsculos ítems como la percepción de que la frontera autor/personaje solo es comprensible en términos de gradualidad. Así, cuando Genette (2004: 137) afirma que la metalepsis tiene lugar cuando el pasaje de un mundo a otro se encuentra enmascarado o subvertido de alguna forma, está aludiendo a todos esos "casos límite" (Gomila, 2013: 3), que nuestro sistema semántico-cognitivo de representación, lastrado por el binarismo aristotélico, no logra procesar al enfrentarse a espectros continuos de gradualidades, lo que nos enfrenta a la paradoja, a la antinomia, de asumir como conciliables ideas a priori contradictorias. Es decir, la lógica difusa valida la afirmación "el autor es y no es el personaje" desde la idea de que la gradación es una herramienta metalingüística, en palabras de Almela Pérez (2003: 64), lo cual supone que la lógica difusa, en cuanto instrumento analítico, hablaría de una mayor o menor 
presencia autorial en los personajes, o en el protagonista en concreto, haciendo de la identidad nominal un autobiografema más - relevante, sí, por la invitación que nos hace de seguir el intrincado camino de las huellas biográficas - dentro de una escala interpretativa que iría desde la ficción absoluta al documento testimonial.

Si echamos un vistazo a la narrativa de Pérez-Reverte, por ejemplo, a quien aludíamos al comienzo de nuestro artículo, hay quien ha señalado precisamente la naturaleza posmoderna de muchas de su novelas (Gómez Laguna, 2015: 122), en el sentido de que el autor asume, desde el punto de vista técnico, la negación de la pureza de las formas y los géneros, a partir de textos en los que localizamos, con distinto grado de presencia, al autor. Esa indeterminación escrituraria, que lleva al propio Pérez-Reverte a jugar con las fronteras difusas entre los géneros - periodístico, novelístico y testimonial en su caso-, supone aceptar que "ningún modo de percibir la realidad pueda ser legitimado sobre el resto" (Gómez Laguna, 2015: 127), negando la existencia de una única verdad. Así, a propósito de Hombres buenos (Pérez-Reverte, 2015), el narrador, quien a su vez actúa como protagonista del relato marco, "es, como él, académico, bibliófilo, fan de Los tres mosqueteros, novelista de éxito con títulos que recuerdan poderosamente a los del propio Pérez-Reverte" (Antón, 2015), lo cual no es óbice para que, como ya hemos indicado, al propio autor juegue al disfraz, afirmando que "es un tipo que se parece a mí, pero no soy yo. Es un artefacto narrativo" (Antón, 2015). El lector, vencido, ha de suspender todo conato de verificación cuando, como en este caso, el propio escritor afirma: "creo ese territorio ambiguo para que no se sepa si es verdad o mentira lo que estoy contando" (Anónimo, 2015).

En resumidas cuentas, la lógica difusa, al asumir la incapacidad analítica, en ocasiones, de sistemas de categorización basados en oposiciones binarias, abre la puerta al universo de la gradualidad, donde los personajes pueden ser y no ser al mismo tiempo los autores reales del texto, desde el margen que da un continuum de huellas autoriales más o menos intensas, en función del texto. Desde este prisma, la cuestión de la identidad nominal entre autor y personaje, crucial por sus consecuencias interpretativas, no deja de ser, sin embargo, un autobiografema más en el universo de los guiños al mundo extraliterario.

\section{CAJAS CHINAS Y AUTOFICCIÓN: ALGUNAS APLICACIONES DE LA TEORÍA DE CONJUNTOS}

Uno de los elementos más valorados por la crítica a la hora de elogiar la celebérrima novela de Javier Cercas (2001), Soldados de Salamina, ha sido su estructura. A propósito de ella, Gómez Trueba (2009: 72-73) explica cómo, en dicho texto, el Javier Cercas real escribe un relato de ficción, Soldados de Salamina, que contiene un personaje, el Javier Cercas de ficción, que escribe un relato real. En definitiva, el relato real estaría dentro del 
relato de ficción: "el relato ficticio Soldados de Salamina, escrito por el Javier Cercas real, se ve obligado a utilizar las mismas palabras que el relato real del Javier Cercas ficticio".

Uno de los problemas que el lector de textos autoficcionales ha de asumir es el complejo entramado de inclusiones que, con frecuencia, estas narraciones reflejan. Así, novelas en las cuales el autor decide escribir un texto en el cual a su vez nos explica que ha decidido escribir un texto - el mismo o diferente - al cual hace repetidas alusiones a lo largo de la narración dejan al lector en un punto de indefinición ontológica, en el cual no acierta a precisar su posición en cuanto instancia receptora de un texto que en realidad es una intrincada maraña de actos comunicativos, consecuencia de un autobiografismo más o menos fingido:

En rigor la especificidad del acto narrativo autobiográfico radica en que no es posible en él delimitar fácilmente la metáfora espacial dentro/ fuera, ni por consiguiente el doble estatuto epistemológico de lo asertivo y lo performativo [...] El acto narrativo autobiográfico tiende a fundir, a unir en uno solo esos dos espacios, de modo que la "verdad revelada" y la "confesión afirmada" proceden del mismo acto, tienen idéntica fuente [...] El acto confesional (performativo) y el acto asertivo-cognoscitivo (narración de hechos) son el mismo, tienen idéntica fuente y se dan en simultaneidad. Ello implica que la valoración que hagamos del segundo se ejecute siempre en el marco del primero. Si fuese posible separarlos habríamos escindido en dos el acto narrativo y el narrador mismo [...] La singularidad del acto narrativo autobiográfico radica en que autor, narrador y personaje se constituyen en el mismo acto y en simultaneidad. Ello confiere al género un estatuto ontológico particular: no se puede "poner en cuestión" lo dicho por el narrador en tanto su estatuto es el de personaje, sin poner en cuestión a la vez al propio narrador (Pozuelo Yvancos, 2001: 46-47).

Si bien la autoficción juega el discurso ambiguo de la indefinición acerca de la identificación entre protagonista/personaje y autor, lo cierto es que comparte con el autobiografismo no solo la dificultad para separar lo textual de lo factual, sino el carácter inclusivo de la enunciación, en la medida en que el personaje es asumido por el narrador, y este a su vez por el autor real. Incluso, en términos de género, podría decirse, con Alberca (2005-2006: 117), que la autoficción puede camuflar un relato autobiográfico bajo la denominación de una novela o puede simular que una novela parezca una autobiografía sin serlo.

En cualquier caso, uno de los retos de la autoficción es entender que, de una u otra manera, el autor juega a, o finge, asumir el discurso del narrador y el del personaje, pero 
al mismo tiempo se distancia de ellos. Si personaje y narrador, por tanto, son y no son al mismo tiempo el autor y si el texto se sitúa "de forma desafiante en el quicio de la frontera que comunica la nación de la ficción con la nación de la autobiografía, sin querer pertenecer en teoría plenamente a ninguna" (Alberca, 2007: 162), lo que tenemos ante nuestro ojos es el clásico problema de la teoría general de conjuntos, conocido como paradoja de Russell o paradoja del barbero.

En términos sencillos, la paradoja de Russell (Cardona, 2007: 173-174) plantea el problema al que nos enfrentamos con aquellos conjuntos que, a diferencia de los habituales, se contienen a sí mismos. Russell (Cardona, 2007: 173-174) ejemplificaba de forma ilustrativa esta cuestión con el ejemplo de un pueblo en el cual el barbero afeitaba a todos aquellos que no pudieran hacerlo por sí mismos. La cuestión, sin embargo, consistía en saber quién había de afeitar al propio barbero, puesto que, en puridad, si se rasuraba a sí mismo, podría afeitarse sin ayuda de nadie, en cuyo caso él no debería hacerlo, pero, de no afeitarse, cumpliría la condición necesaria para ser afeitado por el barbero del pueblo, es decir, él mismo. El problema que aquí Russell (Cardona, 2007: 173174) sacaba a relucir era, no ya el de los denominados conjuntos normales - grupos formados por reuniones de cosas-, sino el de los conjuntos singulares, esto es, aquellos que se contienen a sí mismos, como por ejemplo una bolsa de bolsas. Está claro que todo conjunto ha de ser normal o singular. Ahora bien, el conjunto de todos los conjuntos normales, ¿qué clase de conjunto sería? Si es normal, estará dentro del conjunto de conjuntos normales, luego ya no puede ser normal. Si es singular, no puede estar dentro del conjunto de conjuntos normales, puesto que entonces no se contendría a sí mismo, y si no se contiene a sí mismo entonces no es singular, he ahí el problema.

La piedra de toque en todo este enrevesado laberinto es la cuestión de la representación o, mejor dicho, de la metanarración. En los ejemplos a los que hemos aludido, esto es, Soldados de Salamina y Hombres buenos, de Javier Cercas (2001) y Arturo Pérez-Reverte (2015), respectivamente, asistimos no solo al desarrollo de la narración, sino a la propia explicación novelada del supuesto proceso de elaboración del libro que tenemos ante nuestras manos, y al dejar al desnudo el procedimiento narrativo se "rasga de paso el contrato ficcional, que consiste precisamente en negar el carácter ficcional de la ficción" (Genette, 2004: 27). De este modo, la metalepsis, considerada de forma laxa como "cualquier enunciado acerca de sí mismo" (Genette, 2004: 129), puede volver el foco hacia el autor, convertido así en "novelista entre dos novelas, pero también entre su propio universo vivido, extradiegético por definición, y el intradiegético de su ficción" (Genette, 2004: 36). Para el propio Genette (2004: 15), la metalepsis consistiría en "una manipulación - al menos figural, pero en ocasiones ficcional [...] - de esa peculiar relación causal que une, en alguna de esas direcciones, al autor con su obra, o de modo más general al productor de una representación con la propia representación". De este 
modo, la metalepsis aparecería configurada como un mecanismo narrativo que lleva al lector a saltar un nivel de representación, debido al efecto resultante de evidenciar el propio proceso narrativo, mediante la implicación, de una u otra manera, del autor o del narrador en la historia: "la conducta metaléptica está motivada [...] por una ilusión consistente en tomar como realidad la ficción y tiene por contenido el traspaso ilusorio de la frontera que las separa" (Genette, 2004: 59).

Uno de los puntos clave es precisamente la relación entre la metalepsis de autor y la autoficción, en la medida en que aquella convierte a los autores en héroes de su historia, como si ellos mismos causaran los efectos que pintan o cuentan. Volviendo a la teoría de conjuntos, y a la paradoja del barbero, lo que la metalepsis de autor y la autoficción presentan de algún modo en común es el hecho de pretender convertir al autor real en sujeto literario, y por tanto en protagonista de una historia más o menos ficticia. Es decir, el relato autoficcional —y de ahí su naturaleza paradójica - pasa por el hecho de que el autor real crea una historia con cierto grado de ficcionalidad en la cual él mismo aparece. De este modo, la autoficción sería otro ejemplo de conjunto singular, es decir, de conjunto que se contiene a sí mismo: el autor real — digamos, conjunto $A$ - crea un texto en el cual él mismo aparece: $A$ contiene a $A$. Sin embargo, la diferencia con la autobiografía — que en modo alguno sería un conjunto singular - radica en que en la autoficción el autor crea otra cosa, y no se limita a explicar una parte de su vida. Es decir, en la autobiografía el texto es simplemente una parte seleccionada de la vida del autor, pero en la autoficción el autor se incluye a sí mismo y también añade otros elementos acontecimientos inventados, licencias, etc.- dentro de su actividad literaria. Explicado de forma más sencilla, podríamos decir que la autobiografía es como un coche de un desguace, dentro del cual solo encontramos partes de sí mismo, y la autoficción sería como esa bolsa de bolsas a la que aludíamos antes, esto es, un conjunto singular el cual representa la actividad literaria/inventiva del autor y en el que a su vez podemos encontrar al propio sujeto creador.

Dando un paso más, sería posible incluso relacionar la autoficción en cuanto conjunto singular con la lógica difusa. Peña (1988: 4) consideraba que un conjunto difuso es "un conjunto al que algo pertenece en una medida intermedia entre el grado supremo de verdad y el grado supremo de falsedad [...] un conjunto es difuso cuando ciertas cosas pertenecen al mismo tiempo en una medida ni máxima ni mínima". Otros (Hueso Holgado y Cuervo Díaz, 2013: 32) prefieren hablar de conjuntos borrosos para referirse a esos"conjuntos de bordes poco definidos a los que solo se pertenece en parte e incluyen nociones ambiguas". En cualquier caso, la autoficción nos permitiría aplicar el Principio de gradualidad, según el cual "cualquier cosa posee, aunque solo sea infinitesimalmente, cualquier propiedad" (Peña, 1988: 8). Los textos autoficcionales serían, pues, conjuntos difusos, situados a medio camino del conjunto de textos verídicos y del grupo de obras 
pretendidamente inventadas. Desde su posición, en la autoficción encontraríamos obras con más o menos grado de realidad/ficción, con lo cual la gradualidad afectaría no solo al texto en cuanto totalidad sino a la propia representación del autor real. En los conjuntos difusos se atentaría contra el Principio de no contradicción —algo no puede ser $A$ y no- $A$ al mismo tiempo- desde el momento en el que, por ejemplo, el protagonista es y no es el autor real de la obra. Esta situación, por tanto, nos llevaría de algún modo al ámbito de los mundos imposibles, descritos por Martín-Jiménez (2015: 20) en los siguientes términos: "an impossible world is produced when logical limits are transgressed [...] that marks distinct categories of the textual model of which some of them are put in contact in an incoherent manner". No obstante, como hemos visto, esa transgresión del pensamiento lógico sería consecuencia de la propia consideración de la autoficción en cuanto conjunto singular, lo cual la dota de una especial excepcionalidad.

En conclusión, según la teoría clásica de conjuntos, un conjunto es una colección de objetos que poseen algunas propiedades muy generales, sin tomar en consideración a los objetos individuales, frente a lo cual la visión acerca de los conjuntos manejada por la lógica difusa suponía un paso adelante, al entender el conjunto en cuanto una clase de objetos respecto de la cual un objeto no requiere o bien pertenecer o bien no pertenecer de manera absoluta (Velarde Lombraña, 1996: 435-436). De este modo, la concepción difusa de los conjuntos permite entender cómo en la autoficción el protagonista es y no es al mismo tiempo el autor, debido a la propia configuración de los textos autoficcionales en cuanto conjuntos singulares que se contienen - pero no solo- a sí mismos. Como hemos dicho, esta singularidad de la autoficción la podemos encontrar en autores como Javier Cercas, quien en Soldados de Salamina (2001) y en La velocidad de la luz (2005) "describe el proceso de escribir la misma novela en la que su protagonista —el mismo Cercas - busca el material histórico [...] necesario para la composición de su novela", centrándose de este modo "en el proceso de la creación de la misma novela que el lector tiene en su manos" (Franz, 2009: 32 y 37). Y también Arturo Pérez-Reverte (2006) se beneficiará de la naturaleza paradójica de la configuración autoficcional, al jugar la baza del sí pero no cuando reconoce en El pintor de batallas, por ejemplo, "su propia biografía y su propia mirada pero no la identidad con el protagonista" (Cambosu, 2007: 327), o al referirse a Hombres buenos (2015) diciendo: "la voz narrativa que está contando es un académico que no soy yo. Los libros que él dice que ha escrito no son los que he escrito yo. Pongo distancia para que el lector tenga siempre esa duda" (Anónimo, 2015). De este modo, la autoficción, convertida en una suerte de juego de cajas chinas, da lugar a toda una serie de relatos donde la autoinclusión se convierte en un elemento recurrente, al modo de los versos de Borges (1989: 517) citados al comienzo de La tabla de Flandes (Pérez-Reverte, 1990: 11): “Dios mueve al jugador y este a la pieza / ¿Qué Dios detrás de Dios la trama empieza / De polvo y tiempo y sueños y agonías?" 


\section{AUTORREFERENCIA Y AUTOFICCIÓN: EL PROBLEMA DE LA METALITERATURA}

Una característica fundamental de la autoficción, como ya hemos apuntado, es su naturaleza autorreferencial, es decir, en estas obras con frecuencia el autor no solo construye, de forma más o menos evidente, un sosias que jugamos a desentrañar, sino que alude también al supuesto proceso escriturario que le ha llevado a elaborar el texto que tenemos ante nuestros ojos o, incluso, como en La velocidad de la luz, de Cercas (2005), obras anteriores. Esta autorreferencialidad constituiría, por tanto, un factor crucial que permite volver sobre el sentido paradójico de la autoficción. Así, Vásquez Rocca (2014: 49), en relación a la Paradoja de Epiménides — cretense al que se le atribuye la afirmación: "todos los cretenses son unos mentirosos" - insiste en apuntar que"de la autorreferencia [...] desciende la antinomia: si miento, como afirmo lo que estoy haciendo, pues entonces digo la verdad; pero si digo la verdad, mientras afirmo que miento, entonces estoy mintiendo". Fácil es ver, por tanto, la íntima conexión entre autorreferencia y conjuntos singulares: en ambos casos el enunciado se tiene a sí mismo como sujeto lógico, y de esta situación de inclusión surge, a su vez, la paradoja: $B$ pertenece a $B$ si y solo si $B$ no pertenece a $B$. Tal y como Bertrand Russell (Cardona, 2007: 173-174) había explicado, los conjuntos singulares - aquellos que se contienen a sí mismos - parecen ser miembros de sí mismos si, y únicamente, no son miembros de sí mismos; de ahí la paradoja.

El hecho de enfrentarse a la autorreferencialidad, tal y como ocurre habitualmente en las autoficciones, nos lleva al cuestionamiento de dos pilares fundamentales de la racionalidad, esto es, la idea de identidad y la de no-contradicción:

La autorreferencia se muestra como la referencia de una parte en el conjunto del todo, de tal modo que esta parte designa atributivamente, contiene e incluye, a la totalidad [...] La naturaleza de la autorreferencia muestra en el Arte el límite impreciso entre lógica y estética, tensionado por un princpio de identidad en cuya naturaleza se abre el abismo de su propia crisis lógica, y que hará del Arte una instancia crítica de la razón [...] La ambigüedad autorreferencial es, en lógica, un signo de imperfección, fuente de sofismas, de errores, de contradicciones que denuncian la falta de validez formal; contradicciones que se deben reducir o abolir (Álvarez Falcón, 2010: 32-33 y 41).

Frente a la incomodidad que, para autores como Álvarez Falcón (2010), es atribuible a los fenómenos autorreferenciales, otros prefieren ver en ellos una fuente de inspiración: "para un ordenador, las paradojas autorreferenciales conducen al caos. Se dice que para 
los seres humanos tienen el efecto contrario, pues conducen a la intuición creativa e incluso a la iluminación" (Vásquez Rocca, 2014: 56).

En las metanarraciones, como en las autorreferencias en general, lenguaje y metalenguaje se confunden, a partir de análisis que parecen llevar a callejones sin salida: "la recursividad y los círculos viciosos a los que parece condenado el lenguaje cuando debe dar cuenta de sí mismo, tiene su origen en la relación que, según la tradición metafísica, mantiene con el mundo: estar para tomarlo y ser un reflejo cuidadoso" (Vásquez Rocca, 2014: 44). Sin embargo, como el propio Vásquez Rocca (2014: 98) señala, ya Russell, en su introducción al Tractatus de Wittgenstein (2010: 19), había propuesto como remedio para las paradojas de la autorreferencia la construcción de una jerarquía de metalenguajes, gracias a la cual se dispondría siempre de otro lenguaje que trate de la estructura del primer lenguaje. En nuestro caso, la forma más evidente de escapar a la recursividad que proponen muchas veces las autoficciones, a través del autor/protagonista y/o de la metanarración, sería gracias al lenguaje explicativo de la crítica literaria.

Lo cierto es que no es ningún secreto que el discurso metanarrativo y autorreferencial se ha convertido en una de las técnicas más fecuentes en los relatos contemporáneos, lo cual de algún modo contribuiría a subrayar la condición de artificio verbal de cada producto literario. En esta coyuntura, la literatura autoficcional, al haber"descuidado"toda distinción entre autorreferencia y denotación, entre la designación de síy la designación de algo (Vásquez Rocca, 2014: 51), camina por un sendero en el cual la autorreferencia se convierte a la vez en tesoro y laberinto, es decir, en fuente de riqueza artística e interpretativa, pero también en un quebradero de cabeza para el crítico y el lector. PérezReverte (2015), por ejemplo, verá en Hombres buenos la posibilidad de alternar la trama propiamente dicha con la peripecia creativa del autor mientras da forma a su novela. Para el escritor, este elemento metanarrativo constituirá un filón desaprovechado por él hasta entonces:

Colocar a ese narrador que iba explicando cómo construía la novela me facilitaba ejecutarla de una manera muy complicada estructuralmente y me permitía integrar al lector, ir junto con él, compartir la búsqueda de pistas y datos, hacerle salivar conmigo en el envés de la trama (Antón, 2015).

Es la primera vez que confieso cómo he escrito un libro [...] No lo he dicho nunca, es cierto. Ha sido la primera y quizá sea la última. No lo sé. Ha sido una mera herramienta narrativa. Una novela es un problema narrativo que un escritor tiene que resolver con eficacia. Mientras estaba escribiendo me di cuenta de que esta historia contada linealmente sólo en el pasado tendría momentos monótonos, muertos y poco útiles para una narración eficaz. Entonces decidí crear una estructura que transcurriese en el presente y en el 
pasado. Contar cómo había escrito la novela me permitía hacer saltos, elipsis, referencias, guiños. Darle una mayor eficacia a la estructura. Ese doble plano, presente pasado, en el que transcurre la novela, es una forma de contar que elegí para esta historia. No porque yo quisiera decir "oye, lector, voy a contarte cómo escribo novelas". No, no, no. De hecho todo lo que allí cuento es falso. Es otra ficción dentro de la ficción. Es una falsa realidad (Anónimo, 2015).

La autoficción, por tanto, abre ante nosotros el universo de la autorreferencia y la metanarración. Como conjunto singular que es, al incluir al autor dentro de su propia creación, la autoficción nos deja de nuevo ante la paradoja del cretense, ante el dilema del barbero de Russell (Cardona, 2007: 173-174). Solo la asunción de que el lenguaje explicativo extraliterario, en calidad de metalenguaje ajeno a la encerrona del relato autorreferencial, sirve para elevarnos a un nivel externo al de la recursividad autoficcional nos permite ver que, más allá de una paradoja incómoda y enigmática, la autoficción ofrece una construcción narrativa que atenta contra la lógica ordinaria, pero que no por ello carece de explicación.

\section{ORIENTACIONESPRAGMÁTICAS:LAAUTOFICCIÓN DESDE EL PRISMA RELEVANTISTA}

Aunqueya con la estética de la recepción el papel del lector había adquirido un especial protagonismo en relación con el acto de decodificación de la comunicación literaria, desde que Dan Sperber y Deirdre Wilson (1994) reformularan las máximas conversacionales de Paul Grice (1975), la teoría de la relevancia ha venido cobrando un enorme auge -en detrimento de corrientes anteriores - en el ámbito de la lingüística cognitiva y, por ende, a la hora de analizar los procesos interpretativos con los textos literarios. Grice (1975: 45-46) había ya señalado que la máxima de la relevancia, o de la pertinencia, sustentaba la tendencia del receptor a realizar una implicación conversacional cuando el hablante había aludido a algo que no se desprendía literalmente de su expresión, y que solo era obtenible a partir de la suposición de que había querido decir algo relevante. El aparente incumplimiento de esta y/u otra(s) de las máximas establecidas por Grice (1975) generaba determinados procesos deductivos por parte del receptor, denominados implicaturas, término alusivo a aquellos sentidos obtenidos de un mensaje por parte del receptor, pero divergentes de su sentido literal. De este modo, como los propios Sperber y Wilson (1994:50) reconocen, una de las principales contribuciones de Grice (1975) al ámbito de los estudios pragmáticos habría sido la de demostrar cómo, en el caso de violaciones de las máximas y del principio de cooperación, se espera que los oyentes elaboren cualquier supuesto adicional que sea necesario para resolver satisfactoriamente esa violación. 
Wilson y Sperber (1994) consideraban, por tanto, la relevancia en cuanto la relación que surgía entre la proposición expresada en el enunciado, por un lado, y el grupo de proposiciones que hay en la memoria del oyente, por otro. Así, el emisor del mensaje parte de la presuposición de que su destinatario posee los conocimientos y la competencia necesarios para el correcto desciframiento del mensaje. La teoría de la relevancia, por tanto, centraba su interés en la pericia del receptor a la hora de establecer el contexto más adecuado para la interpretación correcta de la proposición aportada por un enunciado. De este modo, la atribución de intencionalidad a los distintos elementos que conforman una determinada unidad comunicativa llevan al receptor a elaborar implicaturas, esto es, "suposiciones e implicaciones contextuales que el oyente tiene que obtener para asegurarse de que el hablante ha cumplido el Principio de Relevancia" (Yus Ramos, 1997: 113 n.). Desde la perspectiva del receptor, las pautas de análisis, consecuentemente con este planteamiento, obligaban a la existencia de actitudes intencionales detrás de todos y cada uno de los elementos con los que el emisor contaba para configurar su mensaje. Por tanto, este llevaría a cabo actos ostensivos, es decir, actos que implicaban una intención comunicativa, portando en sí mismos la garantía de su relevancia. A partir de aquí, en toda comunicación tendrían lugar dos acciones que se complementarían, y que serían imprescindibles: por un lado, desde la perspectiva del emisor, este realizaría actos ostensivos, es decir, actos intencionales, con un marcado objetivo comunicativo; y, por otra parte, el receptor llevaría a cabo procesos inferenciales, atribuyendo valor significativo a los distintos elementos del mensaje del emisor, presuponiendo que este ha sido realizado de forma óptima y que está configurado con una intención comunicativa. En resumen, el objetivo de la teoría de la relevancia sería desentrañar los mecanismos que permiten recuperar lo que el hablante ha querido comunicar a partir de lo que realmente ha comunicado, partiendo de la presuposición de que el emisor ha tenido la intención de transmitir una información de la mejor de las maneras posibles.

Retomando el hilo del proceso de elaboración literaria, para Pozuelo Yvancos (1993: 51) "la cuestión de la ficción no es metafísica, no es ontológica, es pragmática, resulta del acuerdo con el lector"3. En efecto, el propio Alberca (2005-2006: 116-117) señalaba la importancia que para el lector tiene saber si ha de leer algo como novela o como autobiografía. En este sentido, la equívoca identificación —basada en la habitual coincidencia nominal - entre autor, narrador y protagonista de los textos autoficticios plantearía un tipo de lectura ambigua que "pretende romper los esquemas receptivos del lector, o al menos hacerle vacilar" (Alberca, 2005-2006: 118). Cabría preguntarse, entonces, si ese ambiguo juego identificativo entre las distintas instancias enunciativas

3 Respecto a la cuestión autoficcional, el propio Pozuelo Yvancos (2010) ha dedicado un volumen a analizar los juegos narrativos ofrecidos por autores como Javier Marías y Enrique Vila-Matas. 
busca, en realidad, construir una meditación metanarrativa al objeto de subrayar la condición de artificio verbal de cada producto literario o si, como Alberca (2005-2006: 116-117) sugiere, las novelas autoficticias ofrecen dos modelos interpretativos, como si el autor portara "dos identidades diferentes", a partir de la incertidumbre entre lo real y lo ficticio (Possi, 2014: 156).

En la autoficción, como sabemos, el autor propone un juego en el cual el lector ha de preguntarse si el escritor vivió, o no, los hechos contados. No obstante, en el juego autoficcional habría también una propuesta doble de lectura:

Frente a la actitud del lector puro e inflexible, que rechaza las posiciones intermedias, hay otra de complicidad. Es decir, la del lector que entra en el juego y que no se siente decepcionado por la ambigüedad de la propuesta, al contrario, si entra y acepta esa tesitura de lectura es porque la encuentra fascinante y se deja seducir por el proceso de desvelamiento y ocultación del novelista, por ser invitado a entrar, siempre de manera incierta, en un mundo secreto, el del autor y su vida [...] No saber dónde acaba la ficción y dónde comienza la autobiografía, lejos de ser un impedimento, lo siente como un estímulo (Alberca, 2007: 109-110).

Por tanto, cabría decir que en la autoficción el lector se enfrenta a la sensación de que allí hay "gato encerrado" (Alberca, 2007: 128), a través de una pseudonovela o de una pseudoautobiografía que busca la identidad entre narrador/protagonista y autor $y$, al mismo tiempo, lleva la impronta de una historia novelada, produciendo así un equívoco intencionado en el horizonte de expectativas del lector (Vila Sánchez, 2015: 124):

Descubrir que el nombre del personaje principal de un relato coincide con el del autor pone en funcionamiento de inmediato el pacto autobiográfico y darse cuenta después de que semejante descubrimiento se ha producido en el ámbito de una ficción que se presenta como tal —impidiendo con ello la activación del pacto de veracidad - provoca el desconcierto del lector (Sánchez Zapatero, 2013: 7).

Resulta obvio que no podemos escapar al coqueteo con los datos veraces que muestra el autor - “ ¿es acaso, el yo autoficticio un ente de ficción del mismo tipo que el yo novelesco? Creo que tampoco, pues ha dejado huellas inequívocas de sí mismo, que impiden la desconexión entre el autor y su texto, como es posible en las novelas" (Alberca, 2007: 204)_, pero al mismo tiempo la inclusión en el género novelesco de los 
textos autoficcionales no hace más que recalcar que resulta imposible abandonar los universos referenciales de lo documental y lo fantasioso.

Una de las claves interpretativas más fecundas en el análisis literario es, como sabemos, la adscripción genérica de los textos:

La indicación genérica es, sin duda, muy importante en la aproximación al texto, que autor y editor proponen al lector, pues en teoría lo orientan o lo sitúan en la posición que juzgan más correcta para interpretar con acierto el relato. Vendría a ser algo así como una parte esencial de sus instrucciones de uso (Alberca, 2007: 250).

En este sentido, etiquetar un texto como autoficción supondría enfrentar al lector con un universo de coordenadas que necesariamente nos condicionan en el acto de lectura ${ }^{4}$. Es decir, el término autoficción constituye en sí mismo un acto ostensional, una muestra por parte del escritor, quien nos avisa, diciéndonos, "cuidado, que ni afirmo ni niego nada, sino todo lo contrario". Curiosamente, Ferrero (2013: 3) se pregunta acerca de la naturaleza autoficcional del género lírico, lo cual dependería, en su opinión, de si consideramos, o no, que hay identificación entre el yo lírico y el autor real, o si es una construcción ficcional. Por tanto, la pregunta sería, ¿por qué insistimos tanto en las autoficciones en prosa cuando el género autoficcional por excelencia pudiera ser la poesía?

La autoficción parece, pues, un género literario donde el autor con frecuencia parte de dos explicaciones, esto es, de dos elementos explícitamente comunicados, los cuales a su vez servirán de soporte para los posteriores procesos inferenciales: la categorización del texto en cuanto discurso autoficcional y la identificación - o al menos la no contradicción - nominal entre autor, narrador y personaje. A partir de aquí, y del relato en cuanto acto ostensional del autor, inferimos, o intentamos inferir, las implicaciones derivadas del mensaje literario. En este sentido, lo que habitualmente denominamos vaguedad o ambigüedad del pacto autoficcional no es sino una propuesta literaria con una amplísima gama de implicaciones débiles, esto es, de sugerencias, de invitaciones que plantearía el autor, al objeto de hacernos pensar si algo es verdad o mentira, dejando también la puerta abierta a las "interpretaciones simbólicas" (Puertas Moya, 2005: 319). Álvarez Prendes (2003: 117) ve en ello la máxima expresión de la eficiencia comunicativa:

4 Según Vila Sánchez (2015: 123), para hablar de autoficción el intitulado genérico ha de indicar claramente que se trata de una novela, esto es, de una obra de ficción, a partir de la cual el autor jugaría la baza de los indicios autobiográficos. 
Lavaguedad habráde dejar de ser considerada como una tara o deficiencia dellenguaje natural para pasar a ser considerada como el principal rasgo en el que reside la fuerza y plasticidad del mismo. Su diseño, al menos en lo que a su plano semántico se refiere, se revela como el resultado de una optimización: se han obtenido los máximos beneficios a cambio del menor coste proporcional posible.

De este modo, podría decirse que la autoficción nos enfrenta a una nueva instancia enunciativa, una suerte de autor real figurativo, esto es, un autor ficticio que pretende pasar por el real y que a su vez es el que emana de la voz narrativa, o autorial, en el discurso novelesco. El lector, desde la laxitud interpretativa que ofrece el autor, ha de jugar a escoger sus propias cartas ante la lectura, sin dejarse llevar demasiado por el convencimiento en ninguna de las $\operatorname{manos}^{5}$. De lo contrario, podría ocurrirle lo que a muchos de los lectores de Soldados de Salamina (Cercas, 2001):

No son pocos los que han expresado su disgusto ante la versión de los hechos relacionados con la Guerra Civil española que se ofrecen, $y-$ probablemente confundidos por esa identidad nominal - han achacado al novelista Javier Cercas lo que en realidad cuenta su personaje y, por tanto, deberíamos de pensar que es exclusiva responsabilidad de este (Gómez Trueba, 2009: 77).

Manuel Alberca (2007: 288) se expresará en términos muy parecidos: "también comprendo la reacción de algunos lectores que se sintieron defraudados y hasta timados por ser totalmente crédulos al olvidarse de que en realidad leían una novela, no un libro de historia". De igual modo, y a propósito de Territorio comanche, de Arturo Pérez-Reverte (1994), TVE estuvo a punto de abrir expediente a su entonces empleado amparándose en el hecho de que el libro parecía justificar gastos en zonas de guerra con facturas falsas, fruto, probablemente, de la apreciación de que, "sin ser enteramente una obra biográfica en primera persona, sin embargo, es obvio que tanto la novela como el film reflejan las experiencias propias del autor como reportero de guerra en los Balcanes en los años 90" (Cabezuelo Lorenzo y Cabrera García-Ochoa, 2009: 20)6.

5 En este sentido, la noción de relato factual —en oposición al ficcional—, utilizada por Cercas (2000: 7-18), entre otros, tal y como apunta Tyras (2011:346 n.), no hace más que jugar de nuevo con la alternancia entre los universos extra e intraliterarios, ante lo cual el lector ha de urdir su propia guía de lectura.

6 El propio Pérez-Reverte alimentó el fuego al afirmar, no solo que "siempre y en todos los casos Barlés era Pérez-Reverte", sino que "no había nada de ficción" en el libro (Sánchez Zapatero, 2013: 5). 
La teoría de la relevancia, y en general los análisis amparados en perspectivas pragmáticas, deberían tener una cierta cabida en los estudios sobre autoficción, más allá de categorizaciones formales acerca de la definición del género. Desde el punto de vista relevantista, los textos autoficcionales manifiestan actos ostensivos en lo que concierne a su escritura. Por un lado, la frecuente identificación nominal entre autor, narrador y protagonista, a lo que habría que sumar abundantes guiños a la biografía del escritor. Y por otra parte, el uso habitual - también incluso en ocasiones por parte del propio autor- del marbete autoficción para encuadrar la hoja de ruta que ha de seguir el lector en su labor interpretativa. A partir de ahí, el receptor del texto desarrollaría procesos inferenciales que, como ya hemos apuntado, pasarían por alguna de estas ideas: a) el texto propone una reflexión metaliteraria a partir del juego de espejos entre autor y protagonista; b) el autor busca llevar al lector a la suspensión de todo proceso de verificación, y c) el texto, por sus propias características, busca escapar de la univocidad interpretativa, haciendo así de la lectura un acto más rico y sugerente. De este modo, la teoría de la relevancia nos permite pasar la pelota al tejado del lector, y centrarnos en los procesos inferenciales que, a partir de la ambigüedad autorial, el receptor del texto desarrollaría.

\section{CONCLUSIONES}

La autoficción ha venido planteando en las últimas décadas, en el ámbito del hispanismo, toda una serie de retos a los que la crítica se ha enfrentado, por lo general, desde la preocupación por encontrar una definición laxa, cómoda y aglutinante de un fenómeno incómodo y de difícil asimiento. A partir de ahí, o de forma paralela, se ha buscado una caracterización del hecho autoficcional, en todas sus variantes, al objeto de verificar la pertenencia, o no, de diferentes obras literarias al género. A lo largo del artículo, sin embargo, y a partir de una pequeña selección de textos literarios, comentarios críticos y declaraciones periodísticas, hemos intentado hacer ver al lector cómo diversas orientaciones filosóficas o lingüísticas podrín ayudar a entender mejor la autoficción. En primer lugar, y teniendo en cuenta algunos de los comentarios de escritores y críticos recogidos en estas páginas, los textos autoficcionales parecen presentar con frecuencia una gradualidad en su identificación con las definiciones canónicas que obliga a manejar categorizaciones difusas para entender al ámbito en el que nos movemos. Del es/no es pasamos al un poco de/cierto grado de acerca del autor, lo cual puede ayudar a precisar más nítidamente la caracterización de un texto con rasgos autoficcionales. En segundo lugar, la teoría de conjuntos, y en concreto la paradoja de los conjuntos singulares, esto es, aquellos que forman parte de sí mismos, contribuye a entender mejor el problema irresoluble del sí pero no con el que el autor real se zafa, en ocasiones, de cualquier 
pregunta personal acerca de su texto. A partir de esta singularidad lógica es más sencillo comprender cómo la naturaleza frecuentemente metaliteraria, metanarrativa, de esta clase de obras se sustenta sobre la autorreferencialidad que, al fin y al cabo, es la que explica el desafío lógico de los conjuntos singulares autoincluyentes. Por último, la teoría de la relevancia, en la medida en que se sustenta en el binomio ostensión-inferencia, ayudaría también a comprender cómo la autoficción supone, en cierto modo, elevar a la enésima potencia las implicaturas de un texto literario, y por tanto a su vez la riqueza interpretativa de este.

Respecto a la autoficción, aún queda muchísimo camino por andar, pero el esfuerzo por incorporar nuevas herramientas de análisis no puede sino reportarnos estudios más precisos y reflexiones de mayor calado ante un fenómeno tan complejo y paradójico como rico y estimulante.

\section{REFERENCIAS BIBLIOGRÁFICAS}

AGUSTÍ FARRÉ, A. (2006). "Autobiografía y autoficción". Garoza: Revista de la Sociedad Española de Estudios Literarios de Cultura Popular 6, 9-18.

ALBERCA, M. (1996). "El pacto ambiguo". Boletín de la Unidad de Estudios Biográficos 1, 9-19. (2005-2006). “Existe la autoficción hispanoamericana?" Cuadernos del CILHA 7/8, 115-127. (2007). El pacto ambiguo. De la novela autobiográfica a la autoficción. Madrid: Biblioteca Nueva.

ALMELA PÉREZ, R. (2003). “Bases para una morfología continua del español”. ELUA 17, 57-79.

ÁLVAREZ FALCÓN, L. (2010). “La autorreferencialidad de la experiencia estética”. Fedro. Revista de estética y teoría de las artes 9, 30-42.

ÁLVAREZPRENDES, E. (2003).“El plano semántico del lenguaje: el resultado de una optimización”. Interlingüística 14, 107-118.

AMíCOLA, J. (2009). “Autoficción, una polémica literaria vista desde los márgenes (Borges, Gombrowicz, Copi, Aira)". Oliva 12, 181-197.

ANÓNIMO (2005). Lazarillo de Tormes. Madrid: Cátedra.

(2015). "Pérez-Reverte cuenta la historia de un libro que cambió el mundo". Clarín, 19 de abril, http://www.clarin.com/cultura/Perez-Reverte-Hombres_buenos-Real_ Academia_0_1341466265.html [18/10/2015].

ANTÓN, J. (2015). “Pérez-Reverte: 'He llegado a ver que la gente buena existe'". El País, 14 de marzo, http://cultura.elpais.com/cultura/2015/03/11/babelia/1426079092_003776.html [20/12/2015].

BARTHES, R. (1975). Roland Barthes par Roland Barthes. Paris: Éditions du Seuil.

BORGES, J. L. (1989). Obras completas. Buenos Aires: Emecé, volumen II. 


\section{JOSÉ ANTONIO CALZÓN GARCÍA}

CABEZUELO LORENZO, F. y CABRERA GARCÍA-OCHOA, Y. (2009). “El reportero de guerra en Territorio comanche de Arturo Pérez-Reverte y su adaptación al cine". En Actas del I Congreso Internacional de la Sociedad Latina de Comunicación Social, 1-22. Tenerife: Universidad de La Laguna.

CALZÓN GARCÍA, J. A. (2015). “Construcciones difusas de la identidad. El caso del Lazarillo de Tormes y La velocidad de la luz de Javier Cercas". 452F. Revista de Teoría de la Literatura y Literatura Comparada 13, 134-147.

CAMBOSU, G. (2007). "Autobiografismo negado: El pintor de batallas de Arturo Pérez-Reverte". Boletín de la Real Academia de Extremadura de las Letras y las Artes XV, 327-337.

CARDONA, R. (2007). "La paradoja de Russell y el Quijote". En Actas del Coloquio Internacional “Cervantes y el Quijote", E. Martínez Mata (ed.), 173-178. Madrid: Arco / Libros.

CASAS, A. (2014). El yo fabulado. Nuevas aproximaciones críticas a la autoficción. Madrid / Frankfurt: Iberoamericana / Vervuert.

CERCAS, J. (2000). Relatos reales. Barcelona: Cuaderns Crema. (2001). Soldados de Salamina. Barcelona: Tusquets. (2005). La velocidad de la luz. Barcelona: Tusquets.

COLONNA, V. (2004). Autofiction et Autres mythomanies littéraires. Paris: Tristram.

DARRIEUSSECQ, M. (1996). “L' Autofiction: Un genre pas sérieux". Poétique 107, 369-80

DOUBROVSKY, S. (1977). Fils. Paris: éditions Galilée.

FERRERO, G. (2013). “Autoficciones líricas (Una vez más, el enigma enunciativo)". RECIAL 4, 1-15.

FRANZ, T. R. (2009). "Cercas y Unamuno: La velocidad de la luz y Cómo se hace una novela". Cuadernos de la Cátedra Miguel de Unamuno 47, 2, 31-43.

GASPARINI, P. (2004). Est-il je ?: Roman autobiographique et autofiction. Paris: Éditions du Seuil. GENETTE, G. (1991). Fiction et diction. Paris: Éditions du Seuil. (2004). Metalepsis. De la figura a la ficción. México: Fondo de Cultura Económica.

GRICE, P. (1975). “Logic and conversation". En Syntax and semantics, III. Speech Acts, P. Cole y J. L. Morgan (eds.), 41-48. New York-San Francisco-London: Academic Press.

GÓMEZ LAGUNA, I. (2015). “El Club Dumas de Arturo Pérez-Reverte como paradigma de la narrativa posmoderna española". Dirāsāt Hispānicas 2, 121-136.

GÓMEZ TRUEBA, T. (2009). “Esa bestia omnívora que es el yo: el uso de la autoficción en la obra narrativa de Javier Cercas". Bulletin of Spanish Studies LXXXVI.1, 67-83.

GOMILA, A. (2013). “Los cinco sexos, o cómo establecemos fronteras categoriales moralmente relevantes en un mundo difuso y continuo". ARBOR. Ciencia, Pensamiento y Cultura 189, 762, 1-10.

HUESO HOLGADO, H. y CUERVO DÍAZ, F. (2013). “Lógica borrosa, subjetividad posmodernista y psicoanálisis". Norte de salud mental XI, 31-46.

LARRA, M. J. (2004). Artículos. Madrid: Cátedra. 
LECARME, J. (1993). "L'Autofiction: un mauvais genre?" En Autofictions et cie, 227-248. Paris: Université Paris $X$.

LEJEUNE, P. (1975). Le Pacte autobiographique. Paris: Éditions du Seuil. (1980). Je est un autre. Paris: Éditions du Seuil.

LLUCH PRATS, J. (2006). "La dimensión metaficcional en la narrativa de Javier Cercas". En Actas del XXII Congreso AISPI, 203-306. Madrid: Instituto Cervantes-AISPI.

MANRIQUE SABOGAL, W. (2008). “El yo asalta la literatura”. EI País, 13 de septiembre, http://elpais. com/diario/2008/09/13/babelia/1221262752_850215.html [02/01/2016].

MOLERO DE LA IGLESIA, A. (2000a). Autobiografía y ficción en la novela española actual: J. Semprún, C. Barral, L. Goytisolo, Enriqueta Antolín y A. Muñoz Molina. Berlín: Peter Lang. (2000b). “Autoficción y enunciación autobiográfica”. Signa 9, 531-550 (también en http:// www.cervantesvirtual.com/servlet/SirveObras/13528399434915617422202/p0000006. htm\#I_24_[02/03/2016]).

(2006). "Figuras y significados de la autonovelación". Espéculo 33, http:// pendientedemigracion.ucm.es/info/especulo/numero33/autonove.html [20/12/2015].

MOLINA FOIX, V. (2009). “Larra y su yo”. El País, 2 de mayo, http://elpais.com/diario/2009/05/02/ babelia/1241221150_850215.html [18/12/2015].

MONTREMY, J.-M. (2002). “L'aventure de l'autofiction”. Magazine littéraire 409, 62-64.

PEÑA, L. (1988). "Algunos debates filosóficos sobre los conjuntos difusos". Ideas y Valores 78, 3-27.

PÉREZ-REVERTE, A. (1990). La tabla de Flandes. Madrid: Alfaguara. (1994). Territorio comanche. Madrid: Alfaguara. (2006). El pintor de batallas. Madrid: Alfaguara. (2015). Hombres buenos. Madrid: Alfaguara.

POSSI, V. (2014). “Javier Marías por Javier Marías: autoficción y metanarrativa en Negra espalda del tiempo y Los enamoramientos". Castilla. Estudios de literatura 5, 148-167.

POZUELO YVANCOS, J. M. (1993). Poética de la ficción. Madrid: Síntesis. (2001). “Autobiografía, referencia, performatividad. Un comentario a Paul de Man". En La semiótica actual, 43-48. Sevilla: Ediciones Alfar.

(2010). Figuraciones del yo en la narrativa: Javier Marías y Enrique Vila-Matas. Valladolid: Universidad de Valladolid.

PUERTAS MOYA, F. E. (2005). “Una puesta al día de la teoría autobiográfica como contrato de lectura autobiográfica". Signa 14, 299-330 (también en https://dialnet.unirioja.es/servlet/ articulo?codigo=1456701 [02/03/2016]).

RAMOS ORTEGA, M. J. (2006). “La construcción de las dos últimas novelas de Javier Cercas: Soldados de Salamina y La velocidad de la luz". Tavira: Revista de ciencias de la educación 22, 83-92. 


\section{JOSÉ ANTONIO CALZÓN GARCÍA}

ROMERA CASTILLO, J. (2006). De primera mano. Sobre escritura autobiográfica en España (siglo $X X)$. Madrid: Visor Libros.

(2010). "La escritura (auto)biográfica y el SELITEN@T: guía bibliográfica". Signa 19, 333369 (también en https://digitum.um.es/xm/ui/bitstream/10201/39487/1/1003-3227-1-PB.pdf [01/03/2016]).

RUIZ, J. (2006). Libro de buen amor. Madrid: Cátedra.

SÁNCHEZ ZAPATERO, J. (2013). “¿Hay vida más allá de la autobiografía? Sobre la posibilidad del testimonio en la ficción". Tonos digital: Revista electrónica de estudios filológicos 25, 1-17 (también en https://digitum.um.es/xm/ui/bitstream/10201/39487/1/1003-3227-1-PB.pdf [02/03/2016]).

SPERBER, D. y WILSON, D. (1994). La relevancia: comunicación y procesos cognitivos. Madrid:Visor. TYRAS, G. (2011). "Relato de investigación y novela de la memoria: Soldados de Salamina, de Javier Cercas, y Mala gente que camina, de Benjamín Prado". En nuevos derroteros de la narrativa española actual: veinte años de creación, G. Champeau, J.-F. Carcelén, G. Tyras y F. Valls (coords.), 343-364. Zaragoza: Universidad de Zaragoza.

VÁSQUEZ ROCCA, A. (2014). “Lógica paraconsciente, paradojas y lecturas parasitarias: Del virus del lenguaje a las lógicas difusas". Eikasia: Revista de Filosofía 58, 43-63.

VELARDE LOMBRAÑA, J. (1996). “Pensamiento difuso, pero no confuso: de Aristóteles a Zadeh (y vuelta)". Psicothema 8.2, 435-446.

VILA SÁNCHEZ, J. A. (2015). “La autoficción como dialéctica entre lo histórico y lo biográfico en la obra de Javier Cercas". Pasavento. Revista de Estudios Hispánicos III.1, 123-135 (también en http://www.pasavento.com/pdf/05_09_vilasanchez.pdf [02/03/2016]).

WITTGENSTEIN, L. (2010). Tractatus logico-philosophicus. Madrid: Alianza Editorial.

YUS RAMOS, F. (1997). Cooperación y relevancia. Dos aproximaciones pragmáticas a la interpretación. Alicante: Publicaciones de la Universidad de Alicante.

ZADEH, L. A. (2008). “Is there a need for fuzzy logic?" Information Sciences 178, 2751-2779.

Recibido el 26 de febrero de 2016.

Aceptado el 1 de noviembre de 2016. 